\title{
Graphene-Based Coating for Corrosion Application
}

\author{
Ho Mui Yen, Luther Chong Yuong Qai, Khiew Poi Sim
}

\begin{abstract}
Graphene-based, molybdenum oxide-based and composite coating were prepared by one-step electro-deposition without using aggressive solutions. The coatings were characterised by Scanning Electron Microscope (SEM). The corrosion resistance of the three coatings were evaluated by immersion test (ASTM G31-72), salt spray test (ASTM B117-16) and potentiodynamicpolarisation, in $5 \% \mathrm{NaCl}$ and $2 \% \mathrm{H} 2 \mathrm{SO} 4$ respectively. All of the results indicated that reduced graphene oxide - molybdenum oxide (rGO/MoO) composite coating exhibits the highest corrosion resistance in both saline and acidic environment. This could be ascribed to the synergistic effect of both graphene and molybdenum oxide with the combination of high mechanical strength and superior chemical resistance.
\end{abstract}

\section{INTRODUCTION}

Corrosion can be defined as the deterioration of material which chemically reacts with its surroundings. The chemical reaction takes place in corrosion processes is the reduction and oxidation reaction, which also known as redox reaction [1]. It is estimated that the costs for metallic materials corrosion is $4 \%$ of the gross domestic product of the developed countries [2]. It would be even higher if protection over corrosion were not applied. It is estimated that with the implantation of corrosion protection system, the potential losses related to corrosion could be reduced by a factor of around $30 \%$. Hence, there are several methods applied to prevent or reduce the reaction of corrosion [3].

Graphene is a good candidate for protective layer because of is chemically inertness and thermodynamically stability below $400^{\circ} \mathrm{C}$ [4]. Besides, graphene has the excellent property for the outdoor structure application with the combination of high mechanical strength, good electrical properties, hydrophobic and heat resistance. However, the reduction of Graphene Oxide (GO) to reduced Graphene Oxide (rGO) usually involves many kinds of harmful acids. These acids have brought a lot of bad impacts to the environment. From the standpoint of sustainability, green synthesis method can help reduce the severity of environmental issues. Hence, electrodeposition method without any use of harmful chemicals was suggested [5]. To enhance the corrosion resistance, graphene-molybdenum oxide composite (Gr/Mo) was introduced.

Revised Manuscript Received on April 12, 2019.

Ho Mui Yen, Department of Materials Engineering, Faculty of Engineering and Technology, Tunku Abdul Rahman University College, JalanGenting Kelang, 53300 Kuala Lumpur, Malaysia.

Luther Chong YuongQai, Department of Materials Engineering, Faculty of Engineering and Technology, Tunku Abdul Rahman University College, JalanGenting Kelang, 53300 Kuala Lumpur, Malaysia.

Khiew Poi Sim,Faculty of Engineering, University of Nottingham Malaysia Campus, JalanBroga, 43500 Semenyih, Selangor, Malaysia.

\section{MATERIALS AND METHODS}

The corrosion coupons were chemically treated and then washed gently with distilled water. The steel strip was then connected to the negative terminal which acts as cathode, whereas graphite electrode acts as anode. Then, 3 " height of the steel strip was fully immersed into the electrolyte. During the electroplating process, the solution was constantly stirred to ensure the elements can be dispersed evenly in the electrolyte. In this project, three different coating durations which are 10,20 , and 30 minutes were chosen and three different voltages - 1,2 and $3 \mathrm{~V}$ were applied during electrodeposition process.

The surface morphology and microstructure of the specimens were observed under Scanning Electron Microscope (SEM). Immersion test (ASTM G31-72) was conducted for 10 days to evaluate the corrosion performance of the coated material under a simulated acid rain environment, which is $2 \%$ sulphuric acid. Salt spray test (ASTM B117-16) is simulating sea breeze phenomena by using salt mist (5\% sodium chloride solution) and take advantage of oxygen concentration cell corrosion. The specimens were visually inspected for the forms of corrosion and the location of deposition for 10 days. The cabinet was preconditioned to the operating temperature of $35^{\circ} \mathrm{C}$ and fogging the salt solution at the specified rate of 1 $2 \mathrm{ml} /$ hour.

\section{RESULTS AND DISCUSSION}

The SEM image for the base metal and each type of coating material were shown in Figure 1. Figure 1(a) shows the base metal while Figure 1 (b) and (c) represent graphene and molybdenum oxide coating, respectively. Figure 1(d) demonstrates the co-existence of $\mathrm{Gr}$ and $\mathrm{Mo}$ on the composite coating which proves that the Gr/Mo composite coating was successfully deposited on the base steel. 


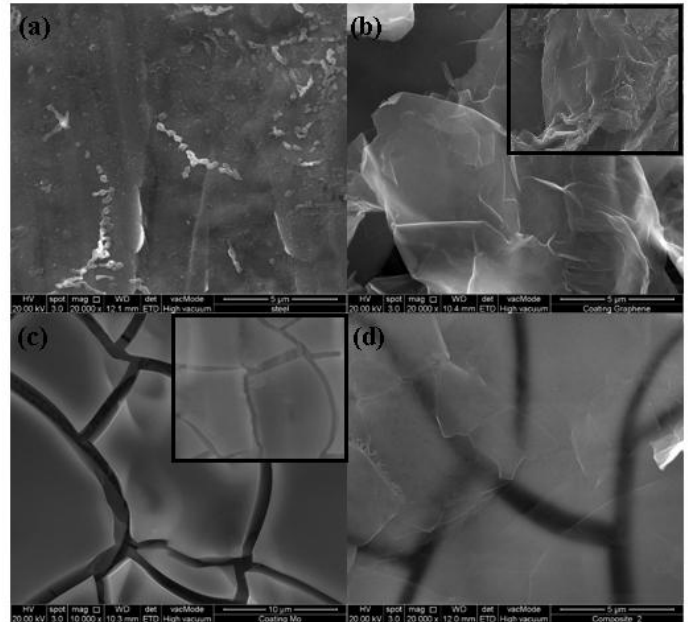

Figure1. (a) SEM image of base steel. (b) SEM image of Gr-coated sample, (inset) Gr coating as abstractedfrom a journal, by Atta et. al.,2015. (c) SEM image for Mocoated sample, (inset) molybdenum coating abstarctedfrom.a journal, by Dauletbay, A, 2016. (d) SEM image for Gr/Mo composite coating.

Figure 2 shows the observation of various type specimens at different exposure duration under $2 \% \mathrm{H}_{2} \mathrm{SO}_{4}$ solution.It is observed in Figure 2 (a) that uncoated specimen encountered the severest corrosion while Gr/Mo composite coated specimen shows the least corrosion. Figure 2 (b) summarises the corrosion rate of base metal and the three coating materials with different coating parameters. Comparing to molybdenum coating, graphene coating shows a better corrosion resistance performance. This may be due to the arrangement hexagonal pattern which enhances the chemical stability of graphene, enabling it to resist chemical attack under ambient conditions [6]. Gr/ Mo composite coatings able to reduce the corrosion rate of base metal by at least $53 \%$.

Figure 3 (a) shows the aesthetic appearance of specimens while Figure 3(b) demonstrates the corrosion rate at different exposure during under saline $(\mathrm{NaCl})$ environment. By observing the aesthetic appearance of the corrosion coupon in Day 10, the ranking of corrosion severity for the specimen is base metal, with the most serious corrosion damage, followed by graphene coated specimen and molybdenum coated specimen. Gr/Mo composite coating demonstrates the best anti-corrosion performance in Salt Spray test which is consistent with the results of immersion test. This phenomena can be ascribed to the synergetic effect of graphene and molybdenum. The excellent adhesion of molybdenum coating decreases the degree of permeability for external substance to diffuse through the coating while graphene coating can act as physical barrier to the aggressive ions.

In contrast to the result obtained in immersion test, anticorrosion efficiency for molybdenum coating is $10 \%$ higher (in average) as compared to graphene coating. According to Shreir (1976), corrosion rate of pure molybdenum under 3\% $\mathrm{NaCl}$ atmosphere is $0.01 \mathrm{~mm} / \mathrm{yr}$. This indicates that molybdenum has excellent resistance to saline environment. Oxide film, specifically $\mathrm{MoO}_{3}$, has great resistance to chlorine environment, therefore, slows down the electrochemical reaction [7].This phenomena can be ascribed to high oxygen-containing functional groups of molybdenum coating, which would limit the rate of electron transfer [8].
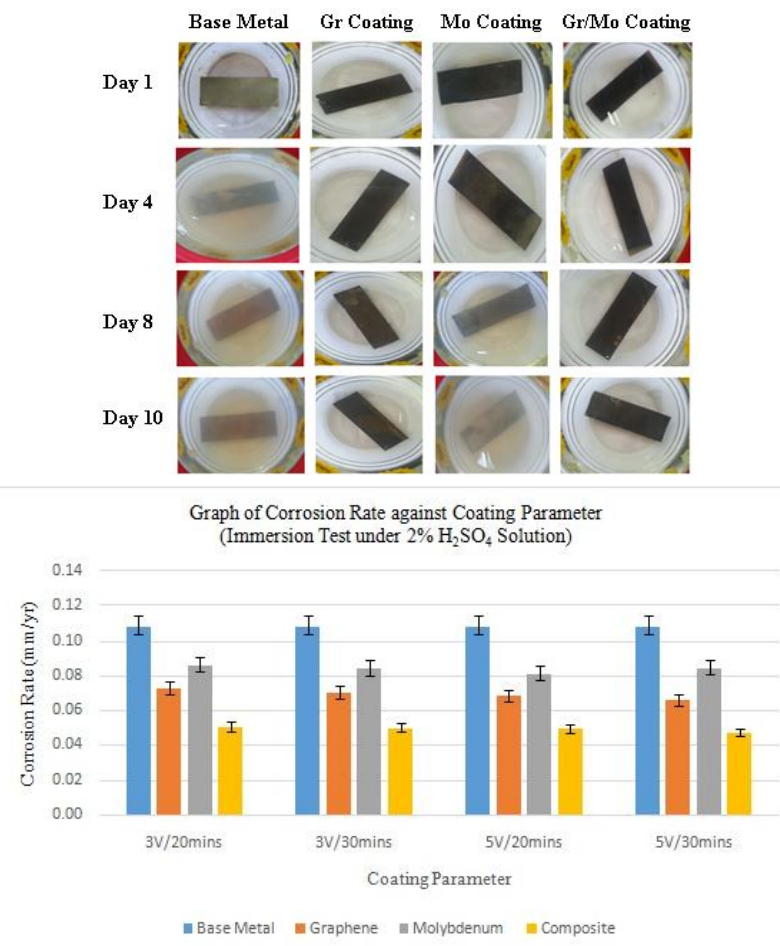

Figure 2: (a) Observation of various type specimens at different exposure time under $2 \% \mathrm{H}_{2} \mathrm{SO}_{4}$ solution, (b) Graph of Corrosion Rate against Coating Parameter, using immersion test in $2 \% \mathrm{H}_{2} \mathrm{SO}_{4}$ Solution.

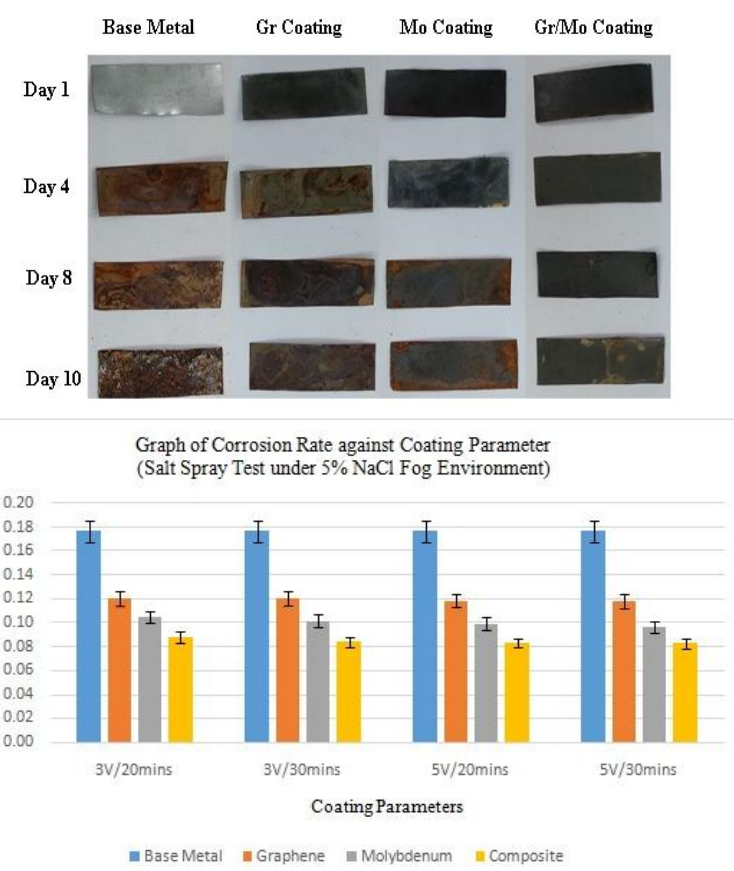

Figure 3: (a) Observation of various type specimens at different exposure time under $5 \% \mathrm{NaCl}$ fog environment (salt spray), (b) Graph of Corrosion Rate against

Coating Parameter, Salt Spray Test under 5\% NaCl Fog Environment (salt spray). 


\section{CONCLUSION}

Graphene- molybdenum oxide composite coating was successfully prepared by one-step electro-deposition without using aggressive solutions. Both immersion test and Salt Spray test demonstrate that the composite coating exhibits the highest corrosion resistance as compared to graphene coating and molybdenum oxide coating.

\section{ACKNOWLEDGEMENT}

The authors would like to acknowledge Tunku Abdul Rahman University College (TAR UC) and University of Nottingham for providing various facilities and advanced equipment in the laboratory.

\section{REFERENCE}

1. Salgado, P., Melin, V., Conteras, D., Moreno, Y., Mansilla, H., Fenton Reaction Driven By Iron Ligands, Journal of the Chilean Chemical Society, vol.58 no.4, p. 4067 (2013).18.

2. Burleigh, D. T.,Corrosion of Steel in a Waterdrop, [Online]. Available: http://infohost.nmt.edu/ burleigh/ (2015).

3. Botana, F.J, Corrosion, [Online]. Available: file:///C:/Users/asus/Downloads/Harvard\%20Referencing0001 .pdf (2015).

4. Mukhopadhyay, P., Gupta, R.K., Graphite, Graphene, and Their Polymer Nanocomposites, [Online], Available: https://books.google.com.my/books?id=s2KKVeKP8f4C\&pg $=$ PA163\&lpg=PA163\&dq=graphene+thermodynamically+sta ble+below+400C\&source=bl\&ots=N24Yhz9yMQ\&sig=2Ah8 _WZ-nDpNeAR8Q4XoC-

JDJVY\&hl=en\&sa $=X \&$ redir_esc $=y \# v=$ onepage $\& \mathrm{q}=$ graphene $\%$ 20thermodynamically\%20stable \%20below\%20400C\&f=fal se (2013).

5. Tassel, T.J.V \& Randall, C.A, 'Mechanism of electrophoretic deposition', Key Engineering Materials, vol. 314, pp. 167-174 (2006).

6. Bodner, The Inorganic Chemistry of Carbon, [Online], Available:

http://chemed.chem.purdue.edu/genchem/topicreview/bp/ch10 /carbon.php (2016).

7. Shreir, L.L., Corrosion: Metal/Environment,[Online], Available: https://books.google.com.my/books?id=FBHBAAAQBAJ\&pg=SA5-PA19\&lpg=SA5-

PA19\&dq=molybdenum + has + good + resistance+to+Chlorie \&s ource=bl\&ots $=y$ V $5 \mathrm{wRyn} x$ aa\&sig=ATVRTwGQsaVVSgStrT QdkuKKEU\&hl=en\&sa=X\&redir_esc $=\mathrm{y} \# \mathrm{v}=$ onepage $\& \mathrm{q}=\mathrm{mol}$ ybdenum $\% 20$ has $\% 20$ good $\% 20$ resistance $\% 20$ to $\% 20$ Chlorie \&f =false (1976).

8. Yu, B., Liu, Y., Zhang, J. and Hai, T., Electrochemical Analysis of Nicotine Based on Multi-Walled Carbon Nanotube/Graphene Composite, International Journal of Electrochemical Science, vol. 11, pp. 4979 - 4987 (2016). 